\title{
Massive gastric necrosis associated with delayed presentation of congenital diaphragmatic hernia-is salvage possible?
}

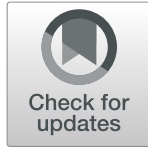

\author{
Krishna Kumar G. (D), Mallikarjun U. and Reshma D.
}

\begin{abstract}
Background: Delayed presentation of congenital diaphragmatic hernia is an uncommon event. Occurrence of gastric volvulus with massive necrosis in this setting is unusual. In this difficult scenario, the surgeon is faced with the dilemma of conservation or resection.
\end{abstract}

Case presentation: A 1-year-old boy with vague gastrointestinal symptoms was found to have congenital diaphragmatic hernia with gastric volvulus, on imaging. The stomach showed massive necrosis secondary to volvulus, and after removal of the necrotic body of the stomach, the remnant was sutured together.

Conclusion: Congenital diaphragmatic hernia is difficult to diagnose in late presenters beyond the neonatal period due to lack of respiratory symptoms. Stomach salvage is feasible even in severe vascular compromise due to extensive collaterals.

Keywords: Gastric necrosis, Congenital diaphragmatic hernia, Delayed presentation

\section{Background}

Congenital diaphragmatic hernia $(\mathrm{CDH})$ is a rare congenital anomaly and typically manifests with respiratory distress occurring immediately after birth or in the first few hours or days of a child's life [1]. Delayed presentation of $\mathrm{CDH}$, beyond the first $24 \mathrm{~h}$ of life, is seen in 10 to $20 \%$ of cases. Presenting symptoms may be quite nonspecific and are often gastrointestinal rather than respiratory in origin [2]. The herniation of the stomach into the hemithorax occurs through a diaphragmatic defect, which may not be sufficiently wide, and when combined with a twist of the stomach in the form of volvulus, compromise of the gastric blood supply is highly likely. In such cases, there can be a diagnostic dilemma in view of the non-specific features. Combination of acute gastric volvulus with $\mathrm{CDH}$ is unusual and hence is a true surgical emergency due to the compromise of blood supply leading onto gastric necrosis [3].

\section{Case presentation}

One-year male child presented with refusal of feeds and retching over the past 2 days, accompanied by irritable cry. On examination child was irritable, with respiratory rate of $42 / \mathrm{min}$ and heart rate of $152 / \mathrm{min}$. On auscultation of the chest, left-sided air entry was decreased. The child was stabilised with supportive care. He was later intubated and ventilated due to worsening respiratory distress. Chest $\mathrm{x}$-ray showed mediastinum shifted to the right side with whiteout of the left hemithorax (Fig. 1). Contrast enhanced computed tomography (CECT) thorax revealed collapsed left lung with non-enhanced stomach wall in the left hemithorax with left pleural effusion (Fig. 2). Diagnosis of left $\mathrm{CDH}$ with gastric volvulus was suspected. After adequate resuscitation and informed written consent, the child was taken up for surgery.

At laparotomy, a $1.5 \times 1.5-\mathrm{cm}$ defect in the left posterolateral diaphragm was noted with stomach, small

* Correspondence: kkpeds@gmail.com

Department of Pediatric Surgery, Jawaharlal Institute of Postgraduate Medical

Education \& Research, Pondicherry 605006, India

Springer Open

(C) The Author(s). 2020 Open Access This article is licensed under a Creative Commons Attribution 4.0 International License, which permits use, sharing, adaptation, distribution and reproduction in any medium or format, as long as you give appropriate credit to the original author(s) and the source, provide a link to the Creative Commons licence, and indicate if changes were made. The images or other third party material in this article are included in the article's Creative Commons licence, unless indicated otherwise in a credit line to the material. If material is not included in the article's Creative Commons licence and your intended use is not permitted by statutory regulation or exceeds the permitted use, you will need to obtain permission directly from the copyright holder. To view a copy of this licence, visit http://creativecommons.org/licenses/by/4.0/. 


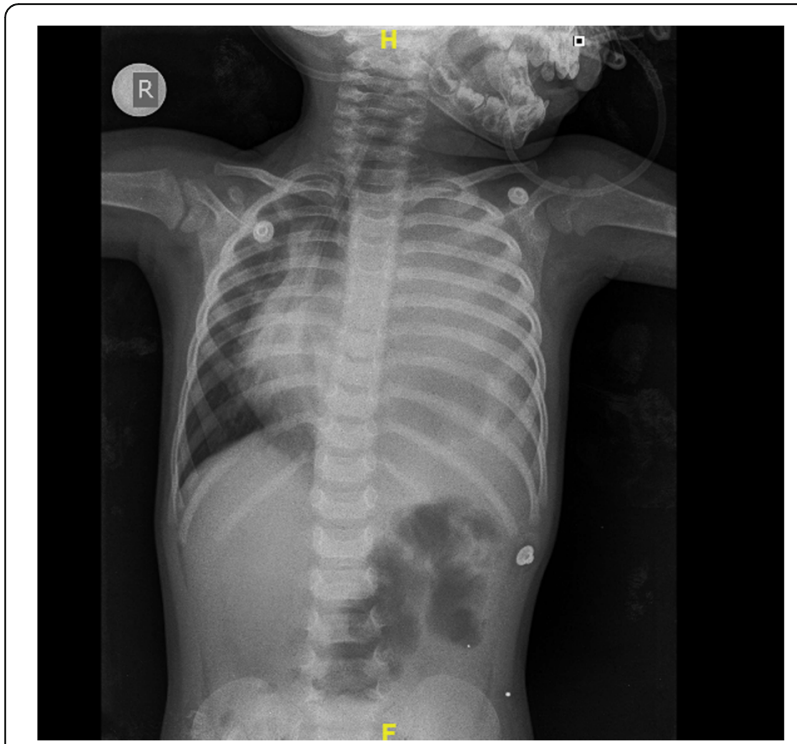

Fig. 1 Pre-operative chest $x$-ray showing shift of mediastinum to the right and whiteout of the left hemithorax

bowel, omentum, and left lobe of the liver as contents. Also, gastric volvulus with massive necrosis was present (Fig. 3). After resection of the necrotic gastric body (nearly $60 \%$ of the total volume of stomach), the residual antrum and fundus were repaired in 2 layers using polyglactin 4-0 sutures. For enteral feed, tube jejunostomy was placed.

Post-operatively, the child was stabilised and weaned off the ventilator. Enteral feeds were administered

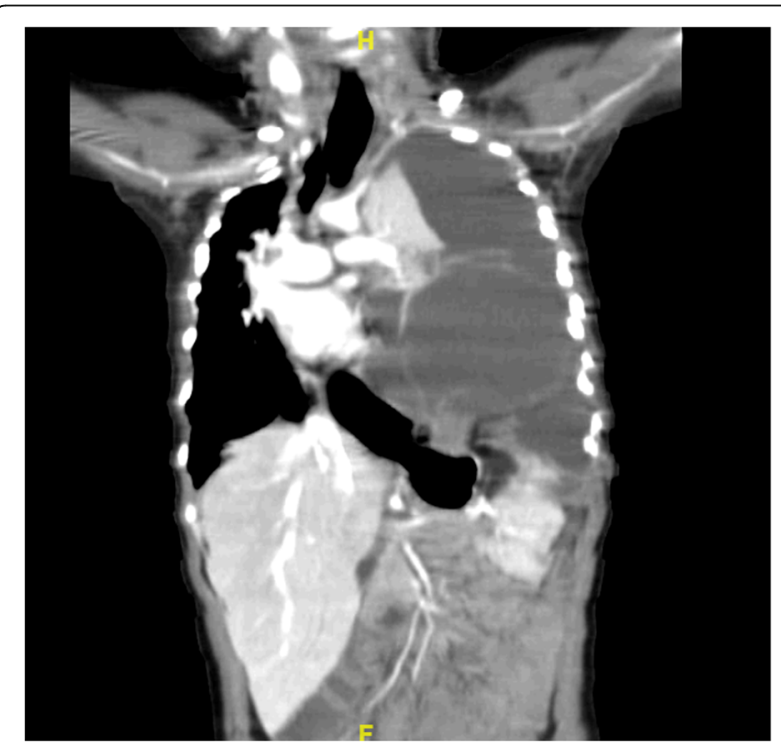

Fig. 2 CECT thorax showing collapsed left lung with non-enhancing wall of the stomach in the left hemithorax through the tube jejunostomy and after 3 weeks oral contrast study showed a small capacity stomach (Fig. 4). Gradually, the child tolerated oral feeds and was discharged. At 1-year follow-up, the child is thriving well.

\section{Discussion}

Gastric volvulus with massive necrosis in the setting of $\mathrm{CDH}$ requires a high index of clinical suspicion for appropriate diagnosis. Literature has only few reported cases. Delay in diagnosis can lead onto significant morbidity such as loss of storage capacity of the stomach. Plain X-ray of the chest with both domes of diaphragm in erect posture is needed to clinch an early diagnosis [3]. In equivocal cases, an upper gastrointestinal contrast study is helpful [4]. Also, CECT scan of the chest with three dimensional reconstructions can clearly show the herniation of abdominal contents into the chest cavity [5]. Abnormal position of the stomach with nonenhancing wall is suggestive of gastric volvulus with compromised blood supply [3].

In the occurrence of massive gastric necrosis, a near total or total gastrectomy may be required, with restoration of esophago-intestinal continuity by anastomosis with residual stomach or interposition of a loop of the small intestine [3]. In our patient, part of the antrum and fundus was viable, which was used to reconstruct the residual stomach. The stomach receives blood supply via the right and left gastric arteries and also the right and left gastro-epiploic arteries. This ensures an excellent and extensive collateral supply allowing organ preservation even in the setting of massive necrosis [6]. Hence, the aim is to do conservative resection, removing only the absolutely nonviable tissue and allow the collaterals to take over the salvage of the gastric remnant. Nevertheless, gastric volvulus has a high mortality rate of $30-50 \%$, and up to $60 \%$ when strangulation or significant vascular compromise is present. An early diagnosis and prompt surgical treatment is required for an uneventful recovery [7].

Shukla et al. [3] report the rarity of massive gastric necrosis in the literature. Of the 2 cases reported in their series, one underwent total gastrectomy and the other partial resection and reconstruction of the stomach. Our case is similar to the second case in terms of gastric salvage, but different from the associated diaphragmatic eventration in both their cases whereas our child had a diaphragmatic hernia.

Strengths of this report include the timely sequence of diagnosis, surgical management and recovery. The inability to document the actual area of vascular demarcation before surgery is a limitation of this case report. 


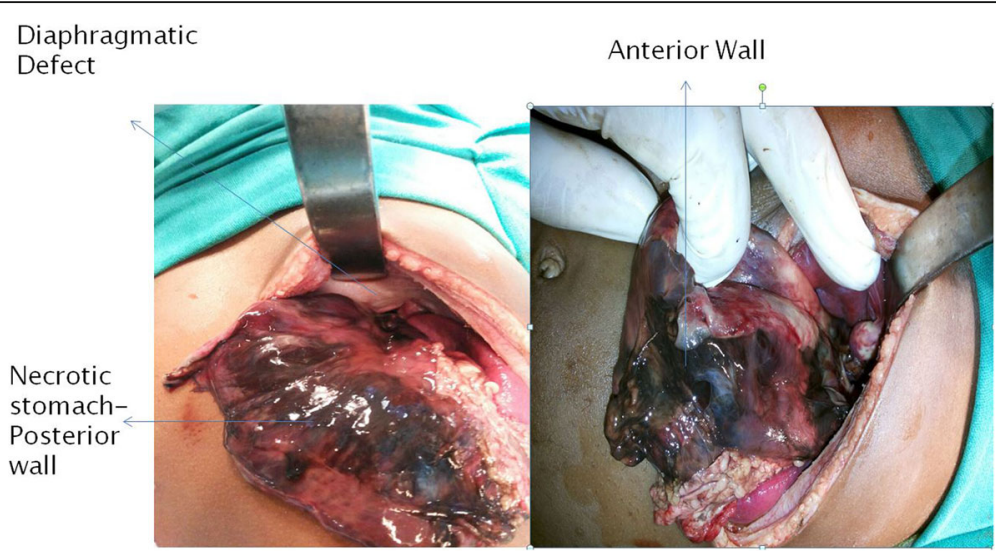

Fig. 3 Intra-operative findings

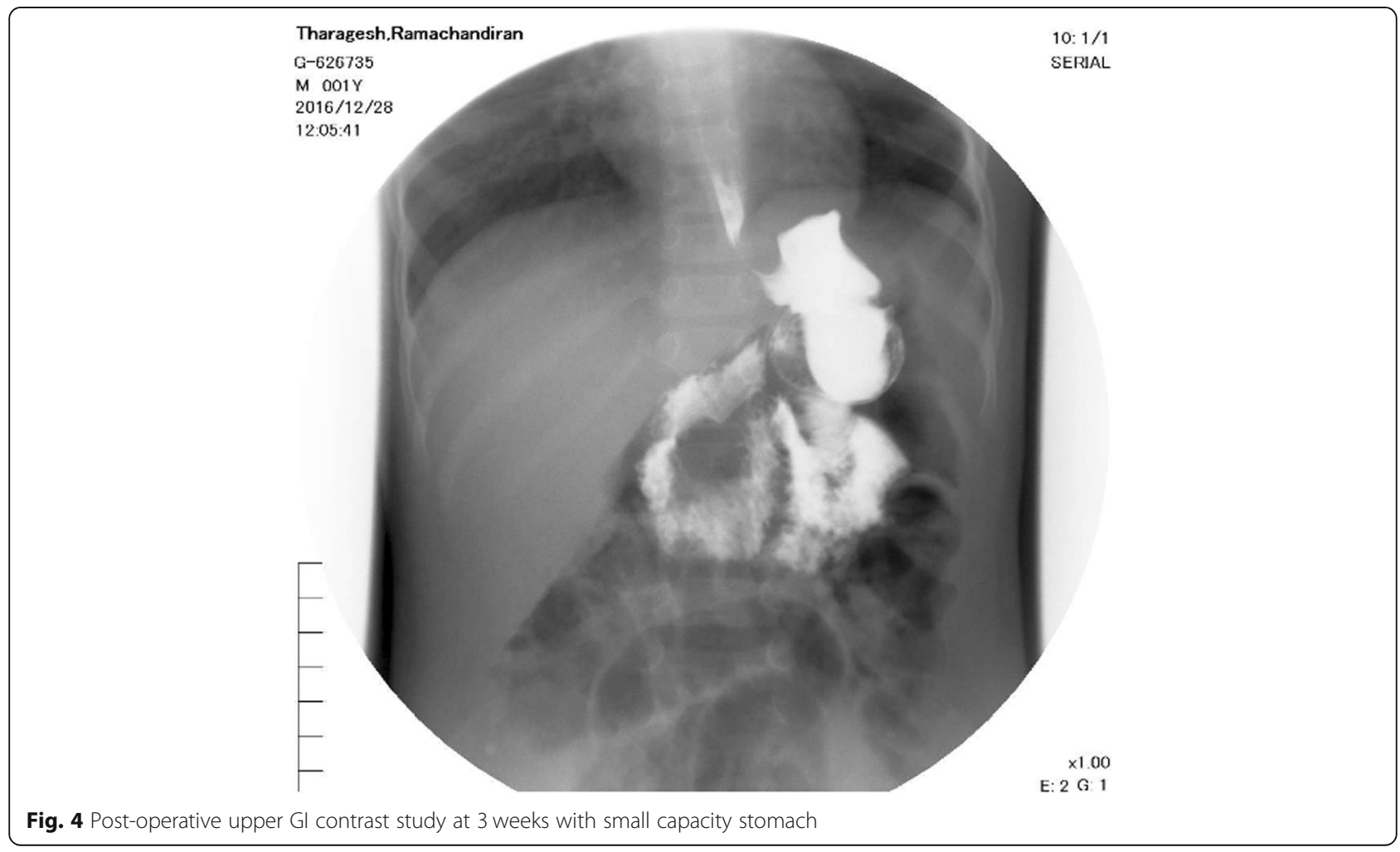




\section{Conclusion}

Delayed presentation of $\mathrm{CDH}$ poses difficulty in diagnosis and use of CECT thorax is valuable. Massive gastric necrosis is a difficult surgical problem, but salvage is still possible due to the rich collateral gastric blood supply.

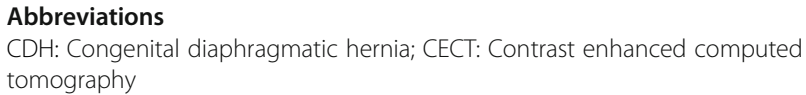

\section{Acknowledgements}

Nil

\section{Authors' contributions}

KG-Principal clinician, overall supervision and review of manuscript.

$\mathrm{MU}$-Collection of patient details, images and references. RD-Manuscript preparation. All authors have read and approved the revised manuscript.

\section{Funding}

$\mathrm{Nil}$

\section{Availability of data and materials}

Available upon request

Ethics approval and consent to participate

Not applicable

\section{Consent for publication}

Written informed consent obtained from the parents. Signed declaration available at request.

\section{Competing interests}

The authors have no conflicts of interest relevant to this article.

Received: 28 April 2020 Accepted: 27 July 2020

Published online: 08 October 2020

\section{References}

1. Nayak HK, Maurya G, Kapoor N, Premashis K. Delayed presentation of congenital diaphragmatic hernia presenting with intrathoracic gastric volvulus. BMJ Case Rep. 2012;007332.

2. Manning PB, Murphy JP, Raynor SC, Ashcraft KW. Congenital diaphragmatic hernia presenting due to gastrointestinal complications. J Pediatr Surg. 1992:27(9):1225-8.

3. Shukla RM, Mandal KC, Maitra S, Ray A, Sarkar R, Mukhopadhyay B, et al. Gastric volvulus with partial and complete gastric necrosis. J Indian Assoc Pediatr Surg. 2014;19:49-51.

4. Singal AK, Vignesh KG, Matthai J. Acute gastric volvulus secondary to eventration of the diaphragm in a child. J Indian Assoc Pediatr Surg. 2006; 11:44-6.

5. Gupta V, Chandra A, Gupta P. Diaphragmatic eventration complicated by gastric volvulus with perforation. S Afr J Surg. 2012;50:90-1.

6. Mahadevan V. Anatomy of the stomach. Surgery. 2017:35(11):608-11.

7. Haas O, Rat P, Christophe M, Friedman S, Favre JP. Surgical results of intrathoracic gastric volvulus complicating hiatal hernia. Br J Surg. 1990;77: 1379-81.

\section{Publisher's Note}

Springer Nature remains neutral with regard to jurisdictional claims in published maps and institutional affiliations.

\section{Submit your manuscript to a SpringerOpen ${ }^{\odot}$ journal and benefit from:}

- Convenient online submission

- Rigorous peer review

- Open access: articles freely available online

- High visibility within the field

- Retaining the copyright to your article 